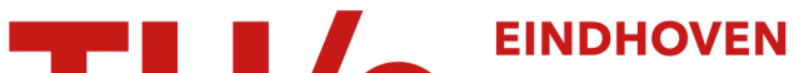 UNIVERSITY OF TECHNOLOGY
}

\section{Preliminary design of a tangentially viewing imaging bolometer for NSTX-U}

Citation for published version (APA):

Peterson, B. J., Sano, R., Reinke, M. L., Canik, J. M., Delgado-Aparicio, L. F., Lore, J. D., Mukai, K., Gray, T. K., van Eden, G. G., \& Jaworski, M. A. (2016). Preliminary design of a tangentially viewing imaging bolometer for NSTX-U. Review of Scientific Instruments, 87(11), 1-4. [11D410]. https://doi.org/10.1063/1.4955278

DOI:

$10.1063 / 1.4955278$

Document status and date:

Published: 01/11/2016

Document Version:

Publisher's PDF, also known as Version of Record (includes final page, issue and volume numbers)

Please check the document version of this publication:

- A submitted manuscript is the version of the article upon submission and before peer-review. There can be important differences between the submitted version and the official published version of record. People interested in the research are advised to contact the author for the final version of the publication, or visit the $\mathrm{DOI}$ to the publisher's website.

- The final author version and the galley proof are versions of the publication after peer review.

- The final published version features the final layout of the paper including the volume, issue and page numbers.

Link to publication

\section{General rights}

Copyright and moral rights for the publications made accessible in the public portal are retained by the authors and/or other copyright owners and it is a condition of accessing publications that users recognise and abide by the legal requirements associated with these rights.

- Users may download and print one copy of any publication from the public portal for the purpose of private study or research.

- You may not further distribute the material or use it for any profit-making activity or commercial gain

- You may freely distribute the URL identifying the publication in the public portal.

If the publication is distributed under the terms of Article $25 \mathrm{fa}$ of the Dutch Copyright Act, indicated by the "Taverne" license above, please follow below link for the End User Agreement:

www.tue.nl/taverne

Take down policy

If you believe that this document breaches copyright please contact us at:

openaccess@tue.nl

providing details and we will investigate your claim. 


\section{Preliminary design of a tangentially viewing imaging bolometer for NSTX-U}

B. J. Peterson, R. Sano, M. L. Reinke, J. M. Canik, L. F. Delgado-Aparicio, J. D. Lore, K. Mukai, T. K. Gray, G. G. van Eden, and M. A. Jaworski

Citation: Rev. Sci. Instrum. 87, 11D410 (2016); doi: 10.1063/1.4955278

View online: http://dx.doi.org/10.1063/1.4955278

View Table of Contents: http://aip.scitation.org/toc/rsi/87/11

Published by the American Institute of Physics

๑ SHIMADZU Powerful, Multi-functional UV-Vis-NIR and Excellence in Science FJis Spectjophotometers

Providing the utmost in sensitivity, accuracy and resolution for applications in materials characterization and science

- Photovoltaics

- Polymers

- Coatings

- Paints

Click here for accurate, cost-effective laboratory solutions
- DNA film structures

- Packaging materials

- Nanotechnology

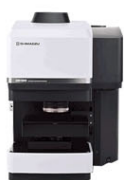

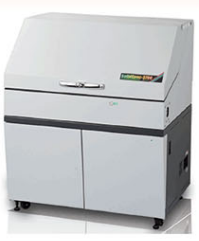




\title{
Preliminary design of a tangentially viewing imaging bolometer for NSTX-U
}

\author{
B. J. Peterson, ${ }^{1,2, a)}$ R. Sano, ${ }^{3}$ M. L. Reinke, ${ }^{4}$ J. M. Canik, ${ }^{4}$ L. F. Delgado-Aparicio, ${ }^{5}$ \\ J. D. Lore, ${ }^{4}$ K. Mukai, ${ }^{1,2}$ T. K. Gray, ${ }^{4}$ G. G. van Eden, ${ }^{6}$ and M. A. Jaworski ${ }^{5}$ \\ ${ }^{1}$ National Institute for Fusion Science, Toki 509-5292, Japan \\ ${ }^{2}$ SOKENDAI (The Graduate University for Advance Studies), Toki 509-5292, Japan \\ ${ }^{3}$ National Institutes for Quantum and Radiological Science and Technology, Naka, Ibaraki 311-0193, Japan \\ ${ }^{4}$ Oak Ridge National Laboratory, Oak Ridge, Tennessee 37831, USA \\ ${ }^{5}$ Princeton Plasma Physics Laboratory, Princeton, New Jersey 08543, USA \\ ${ }^{6}$ FOM Institute DIFFER, 5612 AJ Eindhoven, The Netherlands
}

(Presented 6 June 2016; received 3 June 2016; accepted 13 June 2016; published online 3 August 2016)

The infrared imaging video bolometer (IRVB) measures plasma radiated power images using a thin metal foil. Two different designs with a tangential view of NSTX-U are made assuming a $640 \times 480(1280 \times 1024)$ pixel, $30(105) \mathrm{fps}, 50(20) \mathrm{mK}$, IR camera imaging the $9 \mathrm{~cm} \times 9 \mathrm{~cm} \times 2 \mu \mathrm{m}$ $\mathrm{Pt}$ foil. The foil is divided into $40 \times 40(64 \times 64) \mathrm{IRVB}$ channels. This gives a spatial resolution of 3.4 (2.2) $\mathrm{cm}$ on the machine mid-plane. The noise equivalent power density of the IRVB is given as 113 (46) $\mu \mathrm{W} / \mathrm{cm}^{2}$ for a time resolution of 33 (20) ms. Synthetic images derived from Scrape Off Layer Plasma Simulation data using the IRVB geometry show peak signal levels ranging from $\sim 0.8$ to $\sim 80$ ( $\sim 0.36$ to $\sim 26) \mathrm{mW} / \mathrm{cm}^{2}$. Published by AIP Publishing. [http://dx.doi.org/10.1063/1.4955278]

\section{INTRODUCTION}

The InfraRed imaging Video Bolometer (IRVB) measures plasma radiated power images by using a thin foil to absorb the radiation incident on the foil through a small aperture from the plasma. The radiated power absorbed by the thin metal foil is calculated from the change in the foil temperature using the two dimensional (2D) heat diffusion equation of the foil. The temperature of the foil is measured in 2D using an IR camera viewing the side of the foil opposite to the plasma through a vacuum IR window from outside the vacuum vessel. ${ }^{1}$ Calibration techniques have been developed to determine the spatial variation of the foil thermal parameters $(\kappa$, heat diffusivity, $k t_{f}$ product of heat conductivity, $k$, and foil thickness, $t_{f}$, and $\varepsilon$, black body emissivity of graphite blackened foil), resulting in an absolutely calibrated instrument. ${ }^{2-4}$ In a tokamak, with the assumption of axis-symmetry, a tangentially viewing IRVB can provide numerous lines of sight to be used in a tomographic reconstruction of the $2 \mathrm{D}$ radiation profiles. ${ }^{5}$ Also radiation images can be directly compared to synthetic images derived from an impurity transport model ${ }^{6}$ such as Scrape Off Layer Plasma Simulation (SOLPS $)^{7}$ or EMC3Eirene. ${ }^{89}$ In this paper we give information on the design of an imaging bolometer with a tangential view of NSTXU. ${ }^{10}$ In Section II the IRVB design is described including the choice of the IR camera and the geometry of the bolometer camera. In Section III the sensitivity of the IRVB is quantified through a calculation of the noise equivalent power and the signal is estimated roughly and using synthetic images based

\footnotetext{
Note: Contributed paper, published as part of the Proceedings of the 21st Topical Conference on High-Temperature Plasma Diagnostics, Madison, Wisconsin, USA, June 2016.

a) Author to whom correspondence should be addressed. Electronic mail: peterson@LHD.nifs.ac.jp.
}

on SOLPS data. In Section IV conclusions are drawn and the paper is summarized.

\section{IRVB DESIGN}

The IRVB design consists of (1) the design of the bolometer camera geometry which determines the field of view (FoV) of the IRVB and the number of channels and (2) the choice of the IR camera and the design of the IR optics which are used to bring the IR signal from the foil to the IR camera. In this preliminary design paper the IR optics are neglected and only the FoV is designed.

\section{A. IR camera parameters}

Two different IR cameras are considered in the design of the IRVB. The first is a microbolometer ( $\mu$ bolo) detector based IR camera with the parameters $640 \times 480$ pixels, frame rate of $30 \mathrm{fps}$, and noise equivalent temperature (NET), $\sigma_{I R}$, of $50 \mathrm{mK}$. The second is an InSb detector based IR camera with the parameters $1280 \times 1024$ pixels, frame rate of $105 \mathrm{fps}$ and NET of $20 \mathrm{mK}$. Although the InSb detector is faster and more sensitive than the $\mu$ bolo detector, it is more expensive and the housing tends to be larger and may require more shielding from the magnetic field if it uses an electromechanical cooler. The InSb detector can also be cooled by liquid nitrogen, but this requires extra care and handling and a radioactive environment would require remote supplying of the liquid nitrogen. The $\mu$ bolo detectors are usually fitted with an electromechanical shutter for calibration purposes and these also require additional magnetic shielding, but recently, pneumatically driven shutters have been applied to avoid this problem. In the rest of the paper the parameters for the IRVB with the InSb IR camera are shown in parentheses. 


\section{B. Bolometer camera design}

Both IR camera cases assume a bolometer camera consisting of a $9 \mathrm{~cm} \times 9 \mathrm{~cm}$ Pt foil blackened with graphite with a thickness of $2 \mu \mathrm{m}$. The distance from the $2.6 \mathrm{~mm}$ $\times 2.6 \mathrm{~mm}(1.6 \mathrm{~mm} \times 1.6 \mathrm{~mm})$ aperture (with area, $\left.A_{a p}\right)$ to the foil, $l_{a p-f}$, is $58 \mathrm{~mm}$. The IR camera views the foil radially from a mid-plane port, but the square foil is tilted to face the plasma tangentially, giving a rectangular view of the foil that matches the aspect ratio of the field of view (FOV) of the IR camera. This provides a tangential bolometer FoV of the lower hemisphere of approximately half of the torus of NSTX-U without requiring a tangential port. The $8 \mathrm{~cm} \times 8 \mathrm{~cm}$ central section of the foil is divided into $40 \times 40(64 \times 64)$ IRVB channels, each consisting of 141 (220) IR camera pixels. This gives a spatial resolution of $3.4 \mathrm{~cm}(2.2 \mathrm{~cm})$ on the midplane at the plane of tangency to the central viewing chord. A top view of NSTX-U with the foil and aperture locations and the edges of the field of view is shown in Figure 1. The computer aided drawing (CAD) of the FoV for the $\mu$ bolo case is shown in Figure 2. The FoV for the InSb case is the same except that the number of channels is increased. The top row of channels is centered on the machine mid-plane with the lower rows looking down into the lower divertor. The left hand column of channels views directly into the machine in the major radial direction with the subsequent columns fanning out tangentially.

\section{SIGNAL TO NOISE ESTIMATION}

\section{A. Noise equivalent power estimates}

The noise equivalent power (NEP), $\eta_{I R V B}$, is a figure of merit for the IRVB sensitivity and is derived as Equation (10) in Ref. 1 by propagating the error in the temperature

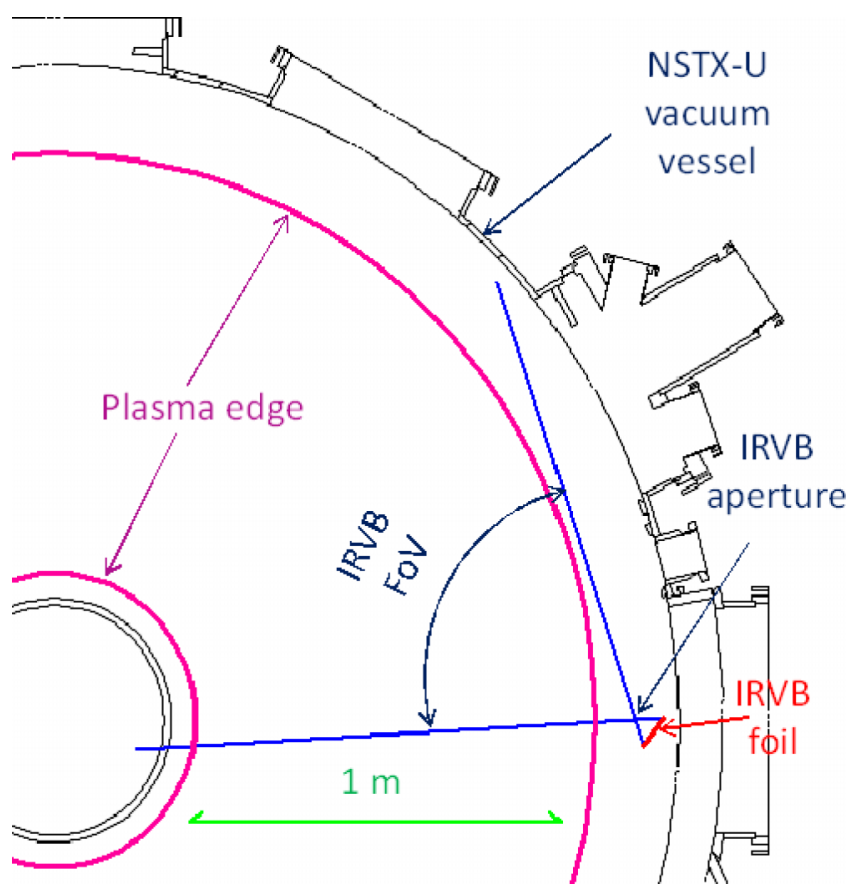

FIG. 1. CAD of top view of NSTX-U midplane showing foil and aperture locations and FoV of IRVB.

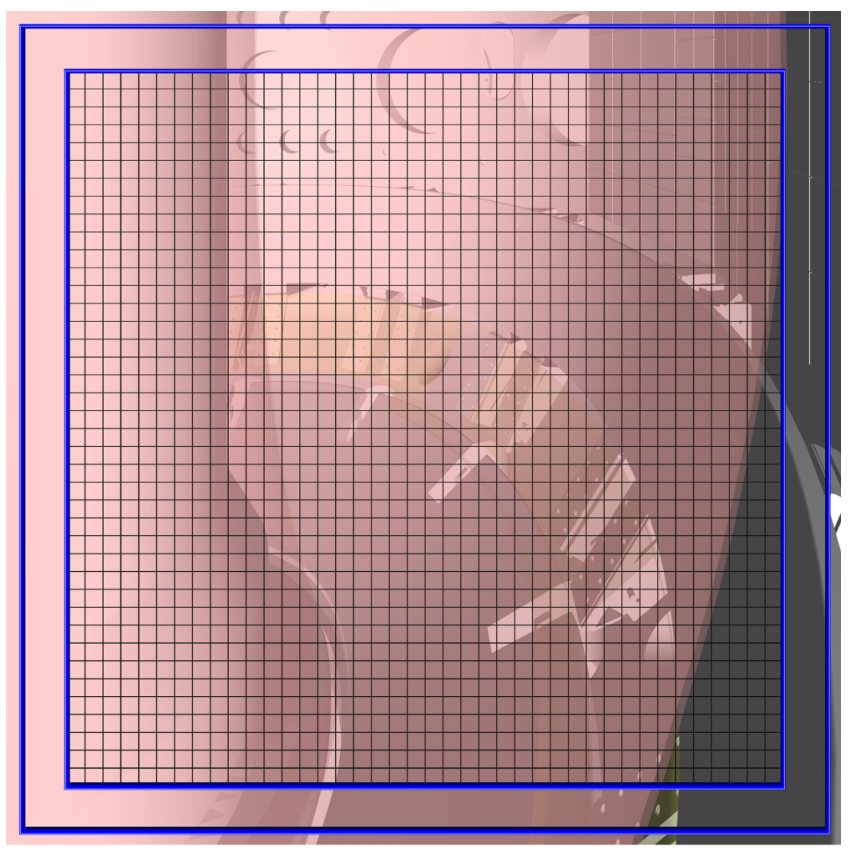

FIG. 2. CAD of FoV of IRVB with tangential view of NSTX-U for $\mu$ bolo case with $40 \times 40$ channels indicated by the gray grid. The plasma is indicated by pink and the blue border lines indicate the $9 \mathrm{~cm} \times 9 \mathrm{~cm}$ edge of the foil and the $8 \mathrm{~cm} \times 8 \mathrm{~cm}$ edge of the usable portion of the foil.

measurement by the IR camera (NET) through the 2D heat diffusion equation of the foil solved for the radiated power. The noise equivalent power density (NEPD), $S_{I R V B}$, is given in the following:

$S_{I R V B}=\frac{\eta_{I R V B} N_{b o l}}{A_{f}}=\frac{\sqrt{10} k t_{f} \sigma_{I R}}{\sqrt{f_{I R} N_{I R}}} \sqrt{\frac{N_{b o l}^{3} f_{b o l}}{A_{f}^{2}}+\frac{N_{b o l} f_{b o l}^{3}}{5 \kappa^{2}}}$,

with $N_{b o l}$, number of bolometer channels, $A_{f}$, utilized area of the foil, $f_{I R}$, frame rate of IR camera, $f_{b o l}$, effective frame rate of bolometer, $N_{I R}$, utilized number of IR camera pixels. Equation (1) is derived from the above mentioned NEP expression by neglecting the black body radiation term (third term under the radical $)$ and dividing by the bolometer pixel area $\left(A_{b o l}\right.$ $\left.=A_{f} / N_{b o l}\right)$. Using this expression the NEPD of the IRVB is given as $113 \mu \mathrm{W} / \mathrm{cm}^{2}\left(46 \mu \mathrm{W} / \mathrm{cm}^{2}\right)$ for a time resolution of $33 \mathrm{~ms}$ (limited by the IR camera frame rate) $(20 \mathrm{~ms})$.

\section{B. Signal estimates}

A rough estimation of the radiated power density at the foil, $S_{\text {signal }}$, is given by

$$
S_{\text {signal }}=\frac{P_{\text {signal }}}{A_{\text {bol }}}=\frac{A_{\text {bol }} A_{a p} \cos ^{4} \vartheta P_{\text {rad }} l_{\text {plasma }}}{A_{\text {bol }} 4 \pi l_{\text {ap-f }}^{2} V_{\text {plasma }}},
$$

where $\theta=20^{\circ}$ is the average angle between the sight line and the foil normal vector. $P_{r a d}=2 \mathrm{MW}$ of radiated power is assumed to be uniformly emanating from the $V_{\text {plasma }}=11 \mathrm{~m}^{3}$ volume plasma. The signal level is therefore estimated to be $5.7 \mathrm{~mW} / \mathrm{cm}^{2}\left(2.2 \mathrm{~mW} / \mathrm{cm}^{2}\right)$. Taking the ratio of Equation (2) divided by Equation (1) gives a signal to noise ratio (SNR) of 51 (48). 

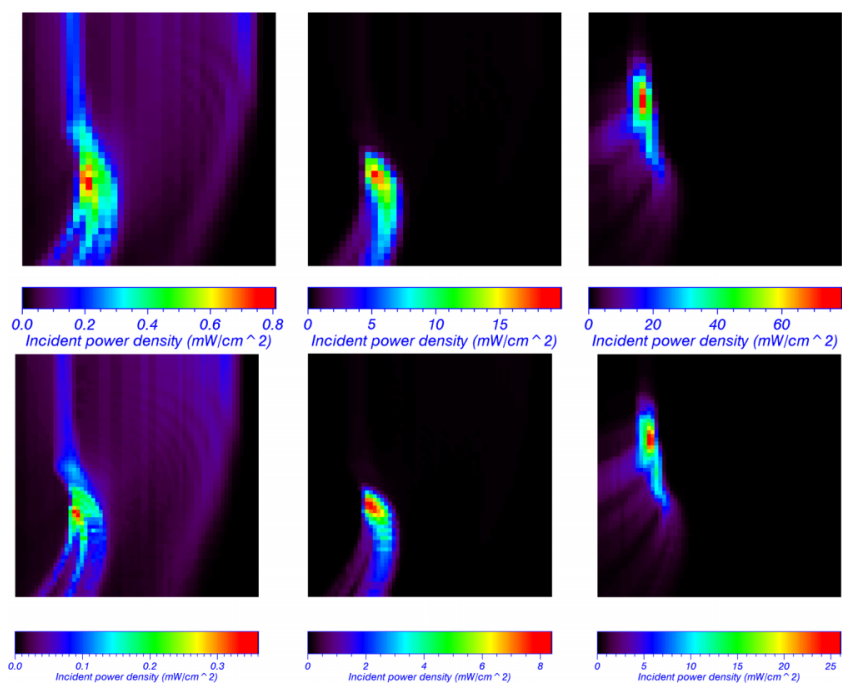

FIG. 3. Synthetic images for carbon and deuterium radiation from SOLPS data for the $\mu$ bolo (upper row, $N_{b o l}=40 \times 40$ ) and InSb (lower row, $N_{b o l}=64$ $\times 64$ ) cases for core densities of 2 (left), 5 (center), and 10 (right) $\times 10^{19} / \mathrm{m}^{3}$.

\section{Synthetic images}

Synthetic images are derived from 2D SOLPS (version 5.0) carbon and deuterium radiation data by assuming toroidal symmetry and integrating the data along the lines of sight of the viewing chords of each IRVB detector (Fig. 3). Three SOLPS cases are considered having input power of $10 \mathrm{MW}$ and core densities of 2,5 , and $10 \times 10^{19} / \mathrm{m}^{3}$, respectively. Peak signal levels range from $\sim 0.8$ to $\sim 80 \mathrm{~mW} / \mathrm{cm}^{2}(\sim 0.36$ to $\sim 26 \mathrm{~mW} / \mathrm{cm}^{2}$ ) depending on the plasma density.

\section{CONCLUSIONS}

These synthetic images demonstrate that the IRVB has sufficient sensitivity and spatial resolution to resolve changes in the radiation structure with density as predicted by SOLPS. The advantage of the larger number of pixels and the higher sensitivity of the InSb detector in resolving the details of the divertor radiation is evident in the comparison with the $\mu$ bolo case. The 1.5 times improvement in spatial resolution for the InSb case is a result of the 2.64 times smaller aperture area, which corresponds to the reduction in signal according to Eq. (2). However, since the IRVB NEPD of the InSb case is also 2.45 times smaller, the InSb case SNR is only slightly smaller. In addition, the InSb case has 1.65 times the temporal resolution of the $\mu$ bolo case. In further design work trade-offs can be made between SNR, spatial, and temporal (down to the hard limit of the IR camera frame time) resolutions to optimize the IRVB for the experimental conditions.

\section{ACKNOWLEDGMENTS}

The authors acknowledge the support of the NSTX-U team and from the National Institute for Fusion Science (Japan) Budget No. NIFS15ULHH026 and the Department of Energy (USA) Contract Nos. DE-AC05-00OR22725 and DE-AC02-09CH11466. One of the authors (B.J.P.) would also like to thank the Department of Energy (USA) and the National Institutes for Natural Sciences (Japan) for financial support during his sabbatical visit to Princeton Plasma Physics Laboratory in 2015.

${ }^{1}$ B. J. Peterson et al., Rev. Sci. Instrum. 74, 2040 (2003).

${ }^{2}$ R. Sano et al., Plasma Fusion Res. 7, 2405039 (2012).

${ }^{3}$ S. N. Pandya et al., Rev. Sci. Instrum. 85, 054902 (2014).

${ }^{4}$ K. Mukai et al., Rev. Sci. Instrum. 85, 11E435 (2014).

${ }^{5}$ B. J. Peterson et al., Plasma Fusion Res. 2, S1018 (2007).

${ }^{6}$ B. J. Peterson et al., J. Nucl. Mater. 415, S1147 (2011).

${ }^{7}$ D. P. Coster et al., Phys. Scr. T104, 7 (2004).

${ }^{8}$ Y. Feng et al., Contrib. Plasma Phys. 44, 57 (2004).

${ }^{9}$ D. Reiter et al., Fusion Sci. Technol. 47, 172 (2005).

${ }^{10}$ M. Ono et al., Nucl. Fusion 55, 073007 (2015). 